\title{
Study of patients absconding behavior in a general hospital at southern region of Iran
}

\author{
Mohammad Khammarnia ${ }^{1}$, Aziz Kassani ${ }^{2}$, Mohammadreza Amiresmaili ${ }^{3}$, Ahmad Sadeghi ${ }^{4}$, Zahra Karimi Jaberi ${ }^{3,4^{*}}$, \\ Zahra Kavosi ${ }^{5}$
}

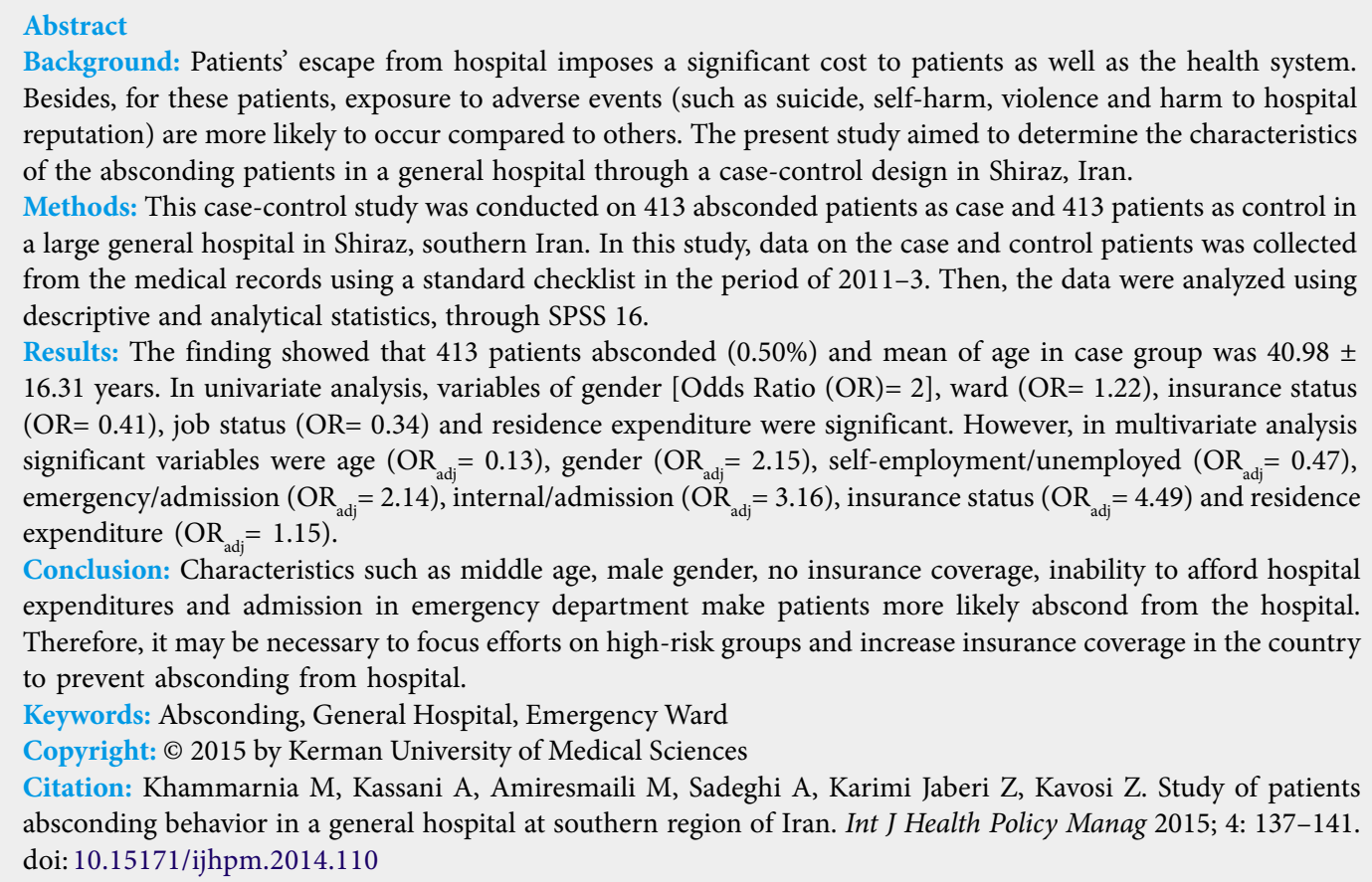

Background: Patients' escape from hospital imposes a significant cost to patients as well as the health system. Besides, for these patients, exposure to adverse events (such as suicide, self-harm, violence and harm to hospital reputation) are more likely to occur compared to others. The present study aimed to determine the characteristics of the absconding patients in a general hospital through a case-control design in Shiraz, Iran.

Methods: This case-control study was conducted on 413 absconded patients as case and 413 patients as control in a large general hospital in Shiraz, southern Iran. In this study, data on the case and control patients was collected from the medical records using a standard checklist in the period of 2011-3. Then, the data were analyzed using descriptive and analytical statistics, through SPSS 16.

Results: The finding showed that 413 patients absconded $(0.50 \%)$ and mean of age in case group was $40.98 \pm$ 16.31 years. In univariate analysis, variables of gender [Odds Ratio $(\mathrm{OR})=2$ ], ward $(\mathrm{OR}=1.22)$, insurance status $(\mathrm{OR}=0.41)$, job status $(\mathrm{OR}=0.34)$ and residence expenditure were significant. However, in multivariate analysis significant variables were age $\left(\mathrm{OR}_{\mathrm{adj}}=0.13\right)$, gender $\left(\mathrm{OR}_{\mathrm{adj}}=2.15\right)$, self-employment/unemployed $\left(O \mathrm{R}_{\mathrm{adj}}=0.47\right)$, emergency/admission $\left(\mathrm{OR}_{\mathrm{adj}}=2.14\right)$, internal/admission $\left(\mathrm{OR}_{\mathrm{adj}}=3.16\right)$, insurance status $\left(\mathrm{OR}_{\mathrm{adj}}=4.49\right)$ and residence expenditure $\left(\mathrm{OR}_{\mathrm{adj}}=1.15\right)$.

Conclusion: Characteristics such as middle age, male gender, no insurance coverage, inability to afford hospital expenditures and admission in emergency department make patients more likely abscond from the hospital. Therefore, it may be necessary to focus efforts on high-risk groups and increase insurance coverage in the country to prevent absconding from hospital.

Keywords: Absconding, General Hospital, Emergency Ward

Copyright: (c) 2015 by Kerman University of Medical Sciences

Citation: Khammarnia M, Kassani A, Amiresmaili M, Sadeghi A, Karimi Jaberi Z, Kavosi Z. Study of patients absconding behavior in a general hospital at southern region of Iran. Int J Health Policy Manag 2015; 4: 137-141. doi: 10.15171/ijhpm.2014.110

\section{Article History:}

Received: 16 June 2014 Accepted: 27 October 2014 ePublished: 30 October 2014

${ }^{*}$ Correspondence to: Zahra Karimi Jaberi Email: zkarimijaberi@gmail.com

\section{Key Messages}

Implications for policy makers

- The rate of absconding is low in the public hospital under study and is approximately like other similar settings. However, according to literature this is high in psychiatric hospitals.

- Lack of insurance coverage makes some people to abscond, which ask policy-makers to focus efforts in order to reach universal coverage.

- Hospital managers should pay attention to hospital wards' entrance for prevention of absconding.

- Hospital personnel should consider the patients with absconding history especially in emergency wards.

Implications for public

Absconding from hospital imposes risk for people particularly for absconded patients' families. Therefore, community should be aware of the absconding risks especially those patients' families. Also, families can increase community security through prevention of the patient absconding.

\section{Introduction}

Absconding, where a patient leaves hospital without informing staff, can be a serious challenge for staff, patients and the hospital system. Patients who leave the hospital without physician permission before completing courses of treatment may cause harm to themselves and others (1). Even if the patients do not make any harm to themselves or others, this maybe a major source of concern for hospital staff (2-4). Patient absconding causes additional costs to the hospital and the patient. These include increased responsibility and workload of hospital staff, the executive manager, and the police department to return the patient to the hospital $(5,6)$. The risks associated with absconding provide a compelling reason to develop tools and strategies to identify potential absconders (6). Four areas of risk associated with absconding are: 1) risk of suicide and self-harm; 2) risk of aggression and violence; 3) risk of self-neglect or death; and 4) risk of loss of confidence to the service and harm to hospital reputation 
(6). The survey of patients characteristics who leave the ward (such as demographic characteristics, disease type, and substance abuse) is an important topic in this field as this provides information as to reasons why patients leave and what strategies might be effective to prevent this phenomenon $(2,6)$. Reported rates of absconding vary. In a literature review, MuirCochrane and Mosel reported absconding rates between 2.5\% to $34 \%$ of all psychiatric admissions (7). Moreover, a study reported that the mean age of absconders was 31.70 years and $95.30 \%$ of absconds were male and the most of them were single (8).

Given that such high rates of absconding occur, with all their attached risks for patients and others, the question arises as to why patients choose to run away from their ward. The previous studies have addressed this topic by interviewing absconders. Muller found that treatment failure (symptoms, medication, and failure of physician - patient relationship) and family problems were the two main reasons driving patients to abscond $(8,9)$. In addition, some cases in the United States have been described that subsistence expenditure was the main cause of absconding (10).

Some studies conducted in psychiatric hospitals in Iran have revealed that risk of absconding is higher in male and single patients (6) and in the early days of admission (5).

However, we were unable to find research regarding the absconding from general hospital and the characteristics of absconders in Iran. Therefore, this study was undertaken to examine patient absconding behavior from wards of a public general hospital in Iran. The objectives were to identify the characteristics of absconding patients, in order to identify possible preventive measures.

\section{Methods}

This case-control study was conducted in a general teaching hospital in Shiraz, which provides both outpatient and inpatient services (374 beds as a large-scale hospital). Shiraz is the fifth most populous city of Iran and the capital of Fars province with a population of over 2 million. Shiraz is located in the Southwest of Iran, and is the center of patient referring in the south of the country. The studied hospital is the second largest hospital of 13 teaching hospitals in the region.

All patients who were admitted to the hospital and absconded over 24-months period (2011 to 2013) were included in the study. Data were collected retrospectively from all absconding patients that the hospital reported. Hospital records were assessed from 22 March 2011 to 14 March 2013 (723 days). The samples consisted of 413 patients who absconded, and a group of 413 patients who considered as a control group. Controls were selected from the same wards, however, if a patient in the same ward did not have the criteria to enter into control group (demographical variables and disease severity), we selected a patient with the same criteria in other wards. Also, another reason for selecting some of control patients from other wards was removing Berkson's bias (11). Hospital patient bias (Berkson's Bias) may occur when hospital controls are used in a case-control study. If the controls are hospitalized due to an exposure (independent variable) that is also related to the outcome under study (patients absconding), then the measure of effect may be weakened, i.e. biased towards the null hypothesis of no association. Therefore, to control Berkson's Bias, some controls were selected from others wards (11). Also, some data of a number of patients were not registered in their records that had been considered as missing data.

Data on the characteristics of absconders and controls were collected from medical records using a standard checklist.

We collected data on socio-demographic variables (such as age, gender, marital status, job, insurance) of the patients which documented in patient profiles in each ward and were available to the researchers.

Data were entered into the SPSS 16 (SPSS Inc., Chicago, IL, USA). For comparison, we grouped the patients as those who absconded and those who did not, and the analysis was completed using Chi-square and T-tests to compare absconders with controls. So variables with significant level below $(P \leq 0.05)$ entered into the logistic regression to remove the effect of confounding variables and to determine related variables with escape of patients.

\section{Results}

A total of 84,420 patients were hospitalized in the study period that 413 of them absconded $(0.50 \%)$. In this study, mean of age in the case group was $40.65 \pm 15.91$ years and in the control group $41.71 \pm 17.70$ years. Mean length of stay (per month) in case and control groups was $5.68 \pm 1.81$ and 4.58 \pm 1.48 days, respectively. Hospital stay expenditure (per day) was $1,157,234 \pm 405,483$ and 465,413 $\pm 20,747$ (Rial) in cases and control groups, respectively. In addition, other characters of individuals are shown in Table 1.

Results of univariate analysis in Tables 1 and 2 reveal that there were significant associations between patient groups and sex, department, insurance and job status.

There was no significant association between age and length of stay and patient groups. The mean length of stay of patients in the absconding group (5.43 days) was higher than the control group (5.39 days).

In multivariate analysis, significant variables $(P \leq 0.05)$ were included in the logistic regression analysis for assessment of possible confounder variables. The results are shown in Table 3.

Logistic regression showed that, variables including age [Odds Ratio $(\mathrm{OR})=1.99]$, gender $(\mathrm{OR}=2.15)$, job $1 \quad(\mathrm{OR}=0.47)$, department $1 \quad(\mathrm{OR}=2.14)$, department $3 \quad(\mathrm{OR}=3.16)$, insurance $(\mathrm{OR}=4.49)$, and residence expenditure $(\mathrm{OR}=1.15)$ were associated with patients escape. Based on these results, middle-aged patient had absconded more than other age groups, male patients had absconded more than female, self-employment had absconded more than unemployed group, and absconding odds in emergency department and internal ward were more than admission ward. Also, noninsured patients absconded more than insured patients, and patients who had high hospital expenditure had absconded more than others. Besides, in the same variables, difference between results (OR crude and OR adjusted) in univariate and multivariate analyses, can be due to role of confounding associations. 
Table 1. Characteristics of absconding patients and non-absconding patients

\begin{tabular}{|c|c|c|c|c|c|c|}
\hline Characteristics & Category & $\begin{array}{l}\text { Case } \\
\text { N (\%) }\end{array}$ & $\begin{array}{c}\text { Control } \\
\text { N (\%) }\end{array}$ & $P$-value & OR crude & Cl 95\% \\
\hline \multirow{2}{*}{ Gender } & Male & $299(56.11)$ & $234(43.90)$ & 0.00 & 2.00 & $1.50-2.68$ \\
\hline & Female & 114 (38.99) & $179(61.10)$ & - & - & - \\
\hline \multirow{2}{*}{ Residence } & Shiraz & $268(49.61)$ & $272(50.49)$ & 0.20 & 0.96 & $0.72-1.28$ \\
\hline & Non-Shiraz & $144(50.59)$ & $141(49.51)$ & - & - & - \\
\hline Escape year & 2012 & $255(47.93)$ & $277(52.17)$ & - & - & - \\
\hline \multirow{5}{*}{ Ward } & Emergency & $269(46.81)$ & 306 (53.29) & 0.01 & 1.22 & $1.06-2.78$ \\
\hline & $\mathrm{ICU}$ & $1(10.00)$ & $9(90.00)$ & 0.00 & 0.03 & $0.01-0.31$ \\
\hline & Internal medicine & $43(50.00)$ & $43(50.00)$ & 0.00 & 0.25 & $0.12-0.41$ \\
\hline & Operation room & $7(35.00)$ & $13(65.00)$ & 0.00 & 0.14 & $0.03-0.64$ \\
\hline & Admission & $12(80.00)$ & $3(20.00)$ & Base & 1.00 & - \\
\hline \multirow{3}{*}{ Marital status } & Married & $213(51.51)$ & $289(69.99)$ & 0.62 & 0.83 & $0.41-1.71$ \\
\hline & Single & $185(44.71)$ & $107(25.91)$ & 0.21 & 1.60 & $0.73-3.36$ \\
\hline & Widow and divorced & $15(03.80)$ & $17(04.20)$ & Base & 1.00 & - \\
\hline \multirow{2}{*}{ Insurance } & No & $272(59.81)$ & $183(40.21)$ & 0.00 & 2.41 & $1.82-3.19$ \\
\hline & Yes & $143(38.11)$ & $232(61.93)$ & - & - & - \\
\hline \multirow{4}{*}{ Job status } & Self-employment & $223(56.22)$ & $174(43.81)$ & 0.44 & 0.76 & $0.37-1.55$ \\
\hline & Housewife & $117(42.26)$ & $160(57.84)$ & 0.21 & 0.43 & $0.20-0.89$ \\
\hline & Government employee & $15(36.64)$ & $26(63.46)$ & 0.02 & 0.34 & $0.13-0.87$ \\
\hline & Unemployed & $22(62.90)$ & $13(37.10)$ & Base & 1.00 & - \\
\hline
\end{tabular}

OR= Odds Ratio; $\mathrm{Cl}=$ Confidence Interval; $\mathrm{ICU}=$ Incentive Care Unit

Table 2. Characterization of demographic variables and its association with patients absconding in case and control groups

\begin{tabular}{|c|c|c|c|c|c|c|}
\hline \multirow{2}{*}{ Variables } & \multicolumn{2}{|c|}{ Case } & \multicolumn{2}{|c|}{ Control } & \multirow{2}{*}{$\mathbf{F}$} & \multirow{2}{*}{$P$-value } \\
\hline & Mean & SD & Mean & SD & & \\
\hline Age (year) & 40.65 & 15.91 & 41.71 & 17.70 & 6.73 & 0.15 \\
\hline Average length of stay (day) & 5.43 & 14.56 & 5.39 & 19.18 & 0.17 & 0.82 \\
\hline Stay expenditure (per day ) & $1,874,605$ & 51,481 & 953,792 & 26,715 & 8.47 & 0.00 \\
\hline
\end{tabular}

$\mathrm{SD}=$ Standard Deviation

\section{Discussion}

This paper reports a retrospective study of absconders from a public teaching hospital over 24 months. The rate of absconding in this hospital was low $(0.50 \%)$, which was similar to studies conducted in other general hospitals $(0.30 \%)$ (12). These rates are significantly lower than psychiatric hospitals or psychiatric wards $(5,12,13)$. For example, the absconding rate was reported about $13.33 \%$ in psychiatric wards in Australia (14) and $14.21 \%$ in India (a non-industrial country) (15). The differences in rates of absconding between general and psychiatric hospitals likely reflect aspects such as differences in patient disorders and hospital environment.

In this study, the male patients in the case group absconded double more than the control group. Several studies indicate that males have more tendency to absconding than females; that was reported about $58.00 \%, 75.00 \%$ and $51.00 \%$ by Meehan et al. (16), Mosel et al. (14) and Sheikhmoonesi et al. (5), respectively. Therefore, the results of other studies confirm our finding.

Moreover, in this study it was found that increasing in the absconding rate is proportionate with age; so that, the mean age of patients who attempted to abscond was 40 years (middle-age) that accords with results of previous study that indicated the majority of patients who absconded of general hospitals are in this age range (39-40 years) (17). However, Meehan et al. showed that $74.00 \%$ of absconders were under 40 years of age and Yasini et al. indicated this was 31.71 years $(6,16)$. In addition, Sheikhmoonesi et al. and Mosel et al. in their studies found that mean age of absconded patients was 31.82 and 25 years, respectively $(5,14)$. Therefore, middle aged and young patients may have more motivation to absconding of general and psychiatric hospitals, respectively (it is worth mentioning that the majority of admitted patients in psychiatric hospitals are youth). Then, it is necessary to pay attention to each group of patients in according to type of hospital especially persons with absconding experience.

The mean number of days for hospitalization was 5.68 days in the case group, although there was no significant difference between case and control groups. The studies conducted by Cheng et al. and Muir-Cochrane et al. showed that the most 
Table 3. Analysis of related variables with patients escape using logistic regression

\begin{tabular}{|c|c|c|c|c|c|}
\hline Variables & Unstandardized coefficient (B) & Standard Error & Wald & OR adjusted & $\mathrm{Cl} \% 95 * *$ \\
\hline Constant & 2.01 & 1.35 & 2.20 & 0.13 & $0.01-0.93$ \\
\hline Age & 0.01 & 0.01 & 1.07 & 1.99 & $1.27-3.01$ \\
\hline Gender (male/female)* & 0.77 & 0.42 & 3.28 & 2.15 & $1.02-4.94$ \\
\hline Residence (Shiraz/non-Shiraz) & 0.16 & 0.23 & 0.48 & 0.84 & $0.53-1.34$ \\
\hline Residence expenditure & 0.01 & 0.01 & 2.10 & 1.02 & $0.98-1.01$ \\
\hline Job 1 (self-employment/unemployed) & 0.74 & 0.54 & 1.90 & 0.47 & $0.16-0.86$ \\
\hline Job 2 (housewife/unemployed) & 1.04 & 0.65 & 2.53 & 0.35 & $0.11-1.27$ \\
\hline Job 3 (government Jobs/unemployed) & 0.42 & 0.79 & 0.28 & 1.52 & $0.32-7.27$ \\
\hline Department 1 (emergency/admission) & 0.76 & 1.06 & 0.51 & 2.14 & $1.26-3.12$ \\
\hline Department 2 (ICU/admission) & 2.06 & 1.52 & 1.83 & 4.84 & $0.14-9.27$ \\
\hline Department 3 (internal ward/admission) & 1.15 & 1.10 & 1.09 & 3.16 & $1.12-5.25$ \\
\hline Department 5 (surgery/admission) & 2.16 & 1.15 & 3.49 & 2.72 & $0.90-18.59$ \\
\hline Insurance (no/yes) & 1.50 & 0.26 & 31.29 & 4.49 & $2.65-7.60$ \\
\hline Escape year & 1.33 & 2.65 & 5.68 & 2.05 & $0.36-4.75$ \\
\hline Stay expenditure (per day ) & 2.15 & 0.36 & 14.97 & 1.15 & $1.02-3.08$ \\
\hline
\end{tabular}

$\mathrm{OR}=$ Odds Ratio; $\mathrm{Cl}=$ Confidence Interval; ICU= Incentive Care Unit

*Note: for each variables, the second category is the reference variable. For example: gender (male/female) which female is base or in job 3 (government jobs/unemployed) unemployed is reference variable.

**Significant level is 0.05 .

absconding occurred within 24 hours after admission $(8,18)$, and the first week after admission was a high-risk period for absconding behavior (16). Therefore, absconding of general and psychiatric hospitals occur in the first and second week after admission, respectively. In general hospitals with open versus close wards in psychiatric hospitals, where the duration of stay is usually short (lower than one week) and the environment is less restrictive, the patients' motivation for absconding is more likely to occur in the first few days of admission.

The present study showed that $46.81 \%$ of patients absconded from the emergency department and this rate in the case group was twice more than the control group; Cheng et al. confirmed this finding and stated that the majority of patients who absconded were admitted through the accident and emergency departments. Since, the emergency department is crowded and sometimes has open door and most high-risk patients refer to this ward for primary treatment, absconding rate in this ward is higher than other wards. Hence, hospital managers should pay more attention to emergency wards than other wards to prevent absconding. In the case group who absconded, residence cost was greater than control group. So, the most likely explanation is that maybe these patients and their families could not afford the treatment costs (10). Khisty et al. found that some patients with low socio-economic status left the hospital with their family members without informing the staff (15). Therefore, the patients who are below the poverty line cannot pay in-patient and treatment cost and to decrease patient absconding, the government should exempt these patients from paying their treatment costs. In addition, in the present study, we found that odds of absconding in unemployed patients versus self- employed in case group was $53.12 \%$ higher than patients in control group, that is similar with the study conducted by Hunt et al. in 2010 (13).

According to the results, the absconding odds ratio in insurance variable was 4.48 which showed that absconding odds in non-insurance versus insured patients in the case group is 4.48 more than the control group. Since, this has not been studied in previous investigations; this may help in identifying those at high-risk.

Although in this study the majority of absconders were married, there was no association with marital status. However, other studies $(6,13)$ in psychiatric hospitals found that single patients absconded more than married patients.

Our results are in keeping with previous studies that have provided a profile of absconders in general, including being male, unemployed and inability to afford charges.

How might administrators' efforts be concentrated to reduce absconding from hospital? Firstly, particular attention could be paid by staff in identifying high-risk patients such as: middle aged, male and uninsured, and this is similar to one study indicated that patients who were more prone to abscond were male and admitted recently (6). Secondly, regular monitoring of wards, especially emergency ward (19). Thirdly, hospital personnel should improve attention and control high-risk patients in the early days after admission (6).

\section{Limitations}

The limitations of the present study were lack of access to absconding patients for interview because of legal issues and missing of the patients' addresses. Therefore, it is suggested for future studies to identify factors associated with absconding through interview with absconding patients to identify 
better strategies to prevent absconding in health system. Moreover, most of the literature discussed about absconding in psychiatric hospital or ward and it was hard to compare our study with them. Nevertheless, the case-control design was suitable for determination of related factors with absconding that can be as an advantage in this study.

\section{Conclusion}

The rate of patient absconding from general hospital was low. However, absconding results in potential risk to patients, community safety, and legal consequences. It may be necessary to focus efforts on all new admissions especially middle-aged men and non-insuranced patients. Moreover, educating the patients at risk of absconding and their families about the consequences of absconding could be crucial in reducing absconding rate. This study can be helpful to predict absconding from hospitals.

\section{Acknowledgments}

We would like to thank the hospital managers and the ethics committee.

\section{Ethical issues}

The study was approved by the ethics committee of the Shiraz University of Medical Sciences (SUMS).

\section{Competing interests}

The authors declare that they have no competing interests.

\section{Authors' contributions}

$\mathrm{MKH}, \mathrm{AK}, \mathrm{AS}$, and ZKJ designed the research; MKH, AK, AS, ZKJ, ZK, and MA contributed to literature searches, analysis of the results and their interpretation; $\mathrm{MKH}, \mathrm{AK}, \mathrm{AS}, \mathrm{MA}, \mathrm{ZKJ}$, and ZK drafted the initial manuscript. MKH AK and ZKJ were the main contributors; other co-authors contributed to specific minor parts by responding to reviewer remarks and recommendations. All authors read and approved the final manuscript.

\section{Authors' affiliations}

${ }^{1}$ Health Promotion Research Center, Zahedan University of Medical Sciences, Zahedan, Iran. ${ }^{2}$ Prevention of Psychosocial Injuries Research Centre, Ilam University of Medical Sciences, Ilam, Iran. ${ }^{3}$ Research Center for Health Services Management, Institute of Futures Studies in Health, Kerman University of Medical Sciences, Kerman, Iran. ${ }^{4}$ Student Research Committee, Shiraz University of Medical Sciences, Shiraz, Iran. ${ }^{5}$ Department of Health Services Management, School of Management and Medical Information, Shiraz University of Medical Sciences, Shiraz, Iran

\section{References}

1. Antebi R. Some characteristics of mental hospital absconders. $\mathrm{Br}$ J Psychiatry 1967; 113: 1087-90. doi: 10.1192/bjp.113.503.1087

2. Bowers L, Simpson A, Alexander J. Real world application of an intervention to reduce absconding. J Psychiatr Ment Health Nurs 2005; 12: 598-602. doi: 10.1111/j.1365-2850.2005.00879.x

3. Bowers L, Jarrett $M$, Clark N, Kiyimba F, McFarlane L. Determinants of absconding by patients on acute psychiatric wards. J Adv Nurs 2000; 32: 644-9. doi: 10.1046/j.13652648.2000.01523.x
4. Stewart D, Bowers L. Absconding and locking ward doors: evidence from the literature. J Psychiatr Ment Health Nurs 2011; 18: 89-93. doi: 10.1111/j.1365-2850.2010.01622.x

5. Sheikhmoonesi F, Kabirzadeh A, Yahyavi ST, Mohseni B. A prospective study of patients absconding from a psychiatric hospital in Iran. Med Glas 2012; 9: 345-9. doi: 10.1016/s09249338(13)75790-0

6. Yasini M, Sedaghat M, Ghasemi Esfe A, Tehranidoost M. Epidemiology of absconding from an Iranian psychiatric centre. $J$ Psychiatr Ment Health Nurs 2009; 16: 153-7. doi: 10.1111/j.13652850.2008.01350.x

7. Muir-Cochrane E, Mosel KA. Absconding: A review of the literature 1996-2008. Int J Ment Health Nurs 2008; 17: 370-8. doi: 10.1111/j.1447-0349.2008.00562.x

8. Cheng S, Chung C, Leung Y, Lai K. Patient absconding behaviour in a public general hospital: retrospective study. Hong Kong Med J 2002; 8: 87-91.

9. Davis B, Bowers L, Jarrett M, Clark N, Kiyimba F, Mcfarlane L. Absconding: why patients leave. J Psychiatr Ment Health Nurs 1999; 6: 199-205. doi: 10.1046/j.1365-2850.1999.630199.x

10. Bowers L, Jarrett M, Clark N. Absconding: a literature review. J Psychiatr Ment Health Nurs 1998; 5: 343-54. doi: 10.1046/j.13652850.1998.00149.x

11. Izquierdo JL, Martínez A, Guzmán E, de Lucas P, Rodríguez JM. Lack of association of ischemic heart disease with COPD when taking into account classical cardiovascular risk factors. Int $J$ Chron Obstruct Pulmon Dis 2010; 5: 387. doi: 10.1111/j.13652850.2008.01350.x

12. Molnar G, Pinchoff DM. Factors in patient elopements from an urban state hospital and strategies for prevention. Psychiatr Serv 1993; 44: 791-2.

13. Hunt IM, Windfuhr K, Swinson N, Shaw J, Appleby L, Kapur N. Suicide amongst psychiatric in-patients who abscond from the ward: a national clinical survey. BMC Psychiatr 2010; 10: 14. doi: $10.1186 / 1471-244 x-10-14$

14. Mosel KA, Gerace A, Muir-Cochrane E. Retrospective analysis of absconding behaviour by acute care consumers in one psychiatric hospital campus in Australia. Int $J$ Ment Health Nurs 2010; 19: 177-85. doi: 10.1111/j.1447-0349.2009.00660.x

15. Khisty N, Raval N, Dhadphale M, Kale K, Javadekar A. A prospective study of patients absconding from a general hospital psychiatry unit in a developing country. J Psychiatr Ment Health Nurs 2008; 15: 458-64. doi: 10.1111/j.1365-2850.2008.01249.x

16. Meehan T, Morrison $P$, McDougall S. Absconding behaviour: an exploratory investigation in an acute inpatient unit. Aust N Z J Psychiatry 1999; 33: 533-7. doi: 10.1080/j.14401614.1999.00603.x

17. Lang UE, Hartmann S, Schulz-Hartmann S, Gudlowski Y, Ricken $\mathrm{R}$, Munk I, et al. Do locked doors in psychiatric hospitals prevent patients from absconding? The European Journal of Psychiatry 2010; 24: 199-204. doi: 10.4321/s0213-61632010000400001

18. Muir-Cochrane E, Oster C, Grotto J, Gerace A, Jones J. The inpatient psychiatric unit as both a safe and unsafe place: Implications for absconding. Int J Ment Health Nurs 2013; 22: 304-12. doi: 10.1111/j.1447-0349.2012.00873.x

19. Gordon JT. Emergency department junior medical staff's knowledge, skills and confidence with psychiatric patients: a survey. Psychiatrist 2012; 36: 186-8. doi: 10.1192/ pb.bp.111.035188 